\title{
Density Functional Theory Study on the Adsorption Mechanism of Sulphide Gas Molecules on $\alpha-\mathrm{Fe}_{2} \mathrm{O}_{3}(001)$ Surface
}

\author{
Li Zhou ${ }^{1,2}$, Huadong Zhu ${ }^{1,2, *}$ and Wen Zeng ${ }^{3, *}$ \\ 1 Research Institute of Natural Gas Technology, Petro China Southwest Oil and Gas Field Company, \\ Chengdu 610213, China; zhou.li@petrochina.com.cn \\ 2 Key Laboratory of Natural Gas Quality Control and Energy Measurement of CNPC, Chengdu 610213, China \\ 3 College of Materials Science and Engineering, Chongqing University, Chongqing 400030, China \\ * Correspondence: zhu_hd@petrochina.com.cn (H.Z.); wenzeng@cqu.edu.cn (W.Z.)
}

check for updates

Citation: Zhou, L.; Zhu, H.; Zeng, W. Density Functional Theory Study on the Adsorption Mechanism of Sulphide Gas Molecules on $\alpha-\mathrm{Fe}_{2} \mathrm{O}_{3}(001)$ Surface. Inorganics 2021, 9, 80. https://doi.org/10.3390/ inorganics 9110080

Academic Editor: Ian Dance

Received: 12 October 2021

Accepted: 3 November 2021

Published: 4 November 2021

Publisher's Note: MDPI stays neutral with regard to jurisdictional claims in published maps and institutional affiliations.

Copyright: (c) 2021 by the authors. Licensee MDPI, Basel, Switzerland. This article is an open access article distributed under the terms and conditions of the Creative Commons Attribution (CC BY) license (https:// creativecommons.org/licenses/by/ $4.0 /)$.

\begin{abstract}
Sulphide gas is an impurity that affects the quality of natural gas, which needs reasonable storage and transportation. In this work, we investigated the adsorption structure and electronic behavior of hydrogen sulfide $\left(\mathrm{H}_{2} \mathrm{~S}\right)$, carbonyl sulfur $(\mathrm{COS})$, and methyl mercaptan $\left(\mathrm{CH}_{3} \mathrm{SH}\right)$ on sulphide gas molecules on pure and vacant $\alpha-\mathrm{Fe}_{2} \mathrm{O}_{3}(001)$ surfaces by density functional theory with geometrical relaxations. The results show that $\mathrm{H}_{2} \mathrm{~S}$ and $\mathrm{CH}_{3} \mathrm{SH}$ are mainly adsorbed in the form of molecules on the pure $\mathrm{Fe}_{2} \mathrm{O}_{3}(001)$ surface. On the vacant $\alpha-\mathrm{Fe}_{2} \mathrm{O}_{3}(001)$ surface, they can be adsorbed on Fe atoms in molecular form and by dissociation. The absolute value of the adsorption energy of $\mathrm{H}_{2} \mathrm{~S}$ and $\mathrm{CH}_{3} \mathrm{SH}$ on the vacancy defect $\alpha-\mathrm{Fe}_{2} \mathrm{O}_{3}$ surface is larger, and the density of states show that the electron orbital hybridization is more significant, and the adsorption is stronger. The charge differential density and Mulliken charge population analysis show that the charge is rearranged and chemical bonds are formed. The affinity of $\mathrm{H}_{2} \mathrm{~S}$ to the vacancy $\alpha-\mathrm{Fe}_{2} \mathrm{O}_{3}(001)$ surface is slightly higher than that of $\mathrm{CH}_{3} \mathrm{SH}$, while $\mathrm{COS}$ molecules basically do not adsorb on the $\alpha-\mathrm{Fe}_{2} \mathrm{O}_{3}(001)$ surface, which may be related to the stable chemical properties of the molecules themselves.
\end{abstract}

Keywords: adsorption; sulphide molecules; $\alpha-\mathrm{Fe}_{2} \mathrm{O}_{3}(001)$ surface; electron

\section{Introduction}

As one of the most important energy sources, natural gas has been more and more widely used in the past few decades [1,2]. However, some sulphide gas impurities will inevitably be introduced into the exploitation of natural gas, such as hydrogen sulfide $\left(\mathrm{H}_{2} \mathrm{~S}\right)$, carbonyl sulfur (COS), and methyl mercaptan $\left(\mathrm{CH}_{3} \mathrm{SH}\right)$ [3-5]. The excessive content of these sulphide gases will seriously corrode the transportation pipeline and storage room, and the leakage will endanger human health and raise safety risks [6-8]. Therefore, in the anticorrosion work, the material selection of gas cylinders and the inhibition of sulphide adsorption are particularly important.

Some iron products, such as pipes and cylinders, are used to transport and store natural gas. Stable $\alpha$-ferric oxide $\left(\alpha-\mathrm{Fe}_{2} \mathrm{O}_{3}\right)$ is formed when iron is placed on the surface in an atmospheric environment for a long time [9]. Transition metal oxide $\alpha-\mathrm{Fe}_{2} \mathrm{O}_{3}$ is not only a stable oxide, but also an n-type semiconductor $[10,11]$. At the same time, $\alpha-\mathrm{Fe}_{2} \mathrm{O}_{3}$ is also used for sulfur removal and has high catalytic activity [12]. From the viewpoint of the microscopic mechanism, the basic study on the interaction between sulphide gas molecules and $\alpha-\mathrm{Fe}_{2} \mathrm{O}_{3}$ surfaces is not only helpful to grasp the adsorption mechanism of sulfides, but also provide a theoretical insight for inhibiting sulphide adsorption, which has extremely important practical significance and scientific research value.

Quantum chemistry methods based on density functional theory (DFT) are increasingly used to clarify the mechanism of adsorption. Song et al. reported the adsorption characteristics of $\mathrm{NO}$ and $\mathrm{H}_{2} \mathrm{O}_{2}$ on perfect and oxygen defect $\alpha-\mathrm{Fe}_{2} \mathrm{O}_{3}(001)$ surfaces. The results show that $\mathrm{NO}$ and $\mathrm{H}_{2} \mathrm{O}_{2}$ are adsorbed on two kinds of surfaces in molecular form, 
while $\mathrm{H}_{2} \mathrm{O}_{2}$ is dissociated on oxygen defect $\alpha-\mathrm{Fe}_{2} \mathrm{O}_{3}(001)$ surfaces [13]. The oxygen vacancy significantly increased the adsorption strength of $\mathrm{NO}$ and $\mathrm{H}_{2} \mathrm{O}_{2}$ on the catalyst surface and promoted the decomposition of $\mathrm{H}_{2} \mathrm{O}_{2}$. Ling et al. investigated the adsorption and decomposition mechanism of $\mathrm{H}_{2} \mathrm{~S}$ on different metal-doped $\alpha-\mathrm{Fe}_{2} \mathrm{O}_{3}(001)$ surfaces. They found that the Fe vacancy surface showed good catalytic activity for the decomposition of $\mathrm{H}_{2} \mathrm{~S}$, and $\mathrm{Zn}$ is beneficial to improve the desulfurization performance [14]. Li et al. discussed the adsorption characteristics of $\mathrm{NO}$ molecules on oxygen-defective and oxygenfree $\alpha-\mathrm{Fe}_{2} \mathrm{O}_{3}(001)$ surfaces, and the two surfaces showed opposite electron transfer [15]. With the introduction of a $\mathrm{NO}$ molecule, the electron carrier concentration decreases and the surface resistance of oxygen defect $\alpha-\mathrm{Fe}_{2} \mathrm{O}_{3}(001)$ increases. Oxygen defects change the direction of electron transfer. Chen et al. calculated the interaction of water and oxygen with the $\alpha-\mathrm{Fe}_{2} \mathrm{O}_{3}(001)$ surface [16]. After the adsorption of $\mathrm{H}_{2} \mathrm{O}$ and $\mathrm{O}_{2}$ molecules, the surface structure of $\mathrm{Fe}_{2} \mathrm{O}_{3}$ changed substantially; the $\mathrm{O}-\mathrm{Fe}$ bond was weakened, and the $\mathrm{H}-\mathrm{O}$ bond of water molecules was broken to form hydroxyl groups. It is difficult to control the point defect in the experiment. Furthermore, this reaction process is difficult to clarify by experimental method. Therefore, the theoretical study can provide a certain guiding significance for in-depth understanding of the adsorption mechanism [17-20]. However, there are rare reports on the adsorption of sulfide gases, especially $\mathrm{H}_{2} \mathrm{~S}, \mathrm{COS}$ and $\mathrm{CH}_{3} \mathrm{SH}$ molecules, on the $\alpha-\mathrm{Fe}_{2} \mathrm{O}_{3}$ surface using first-principle calculation. Little is known about bonding and charge transfer.

In this work, we calculated the sulphide gas molecules' adsorption property on the $\alpha-\mathrm{Fe}_{2} \mathrm{O}_{3}(001)$ surface by using density functional theory, and investigated the possible binding mechanism of sulfides on the $\alpha-\mathrm{Fe}_{2} \mathrm{O}_{3}$ surface. The adsorption configuration, bonding type, and charge transfer between sulfides and substrates were discussed. In addition, the effect of oxygen vacancy on adsorption is fully considered. The information of adsorption energy and electronic parameters described in this paper will provide a meaningful, theoretical understanding for the adsorption of sulfides on the $\alpha-\mathrm{Fe}_{2} \mathrm{O}_{3}$ surface and provide theoretical guidance for anticorrosion or inhibition of adsorption.

\section{Computational Methods and Models}

\subsection{Theoretical Calculation Methods}

All the calculations in this work are based on the DFT calculation method and completed through the CASTEP (Cambridge Sequential Total Energy Package) module of the Materials Studio software [21,22]. Basically, all the calculations are mainly carried out through geometrical relaxations of each model. Using periodic boundary conditions, the electron wave function is expanded through the plane wave basis set [23]. The PBE (Perdew-Burke-Ernzerhof) functional of the GGA (generalized gradient approximation) is selected to deal with the exchange correlation energy of all electrons [24,25]. The ultra-soft pseudopotential is used to describe the ionic nucleus. A BFGS (Broyden-Fletcher-GoldfarbShanno) algorithm is selected in the process of structure optimization [26]. Considering the calculation accuracy and efficiency, the kinetic energy cutoff value of the plane wave basis group is $400 \mathrm{eV}$. After testing different k-point grid schemes, the $3 \times 3 \times 1$ Monkhorst-Pack format k-point grid is used to integrate the Brillouin zone (the k-point setting of $5 \times 5 \times 2$ $\alpha-\mathrm{Fe}_{2} \mathrm{O}_{3}$ unit cell is optimized) [27]. The convergence criteria for structure optimization and energy calculation are set as follows: the self-consistent field (SCF) cycle converges to $2.0 \times 10^{-6} \mathrm{eV} /$ atom; the maximum force convergence value of each atom is $0.05 \mathrm{eV} / \AA$; the maximum internal stress of the crystal is $0.1 \mathrm{GPa}$; and the maximum displacement convergence value of the atom is $0.002 \AA$.

Although the DFT-GGA theory provides accurate lattice constants, it usually underestimates the band gap [28]. The prediction of the $\alpha-\mathrm{Fe}_{2} \mathrm{O}_{3}$ band gap can be improved by a GGA+U calculation $[29,30]$. In addition, in order to achieve the accuracy of calculation, all model calculations in the current work are adopted functional PBE+U. Referring to previous studies [31,32], the spin arrangement of antiferromagnetism $(+--+)$ is set (+ represents spin relative to $z$-axis, - relative to $z$-axis), as shown in Figure 1a. The $\alpha-\mathrm{Fe}_{2} \mathrm{O}_{3}$ of this 
spin arrangement has the lowest energy and the most stable structure [14]. In order to more accurately describe the Coulomb interaction of Fe-3d electronic states, $U=5 \mathrm{eV}$ 's GGA + U method is used to deal with the exchange correlation energy for Fe atoms [33]. The energy bands of bulk $\alpha-\mathrm{Fe}_{2} \mathrm{O}_{3}$ are calculated. The total density of states (DOS) and fractional densities of states (PDOS) are shown in Figure 1b,c. The band gap is $2.20 \mathrm{eV}$, which is in good agreement with the indirect optical energy gap of $1.9-2.2 \mathrm{eV}[34,35]$. The top of the valence band of $\alpha-\mathrm{Fe}_{2} \mathrm{O}_{3}$ is mainly contributed by O-2p, and the bottom of the conduction band is mainly contributed by Fe-3d. The $3 \mathrm{~d}$ orbitals of Fe overlap with the $2 p$ orbitals of $\mathrm{O}$ in a large energy range, and there is hybridization in the range of $2 \sim 3 \mathrm{eV}$.
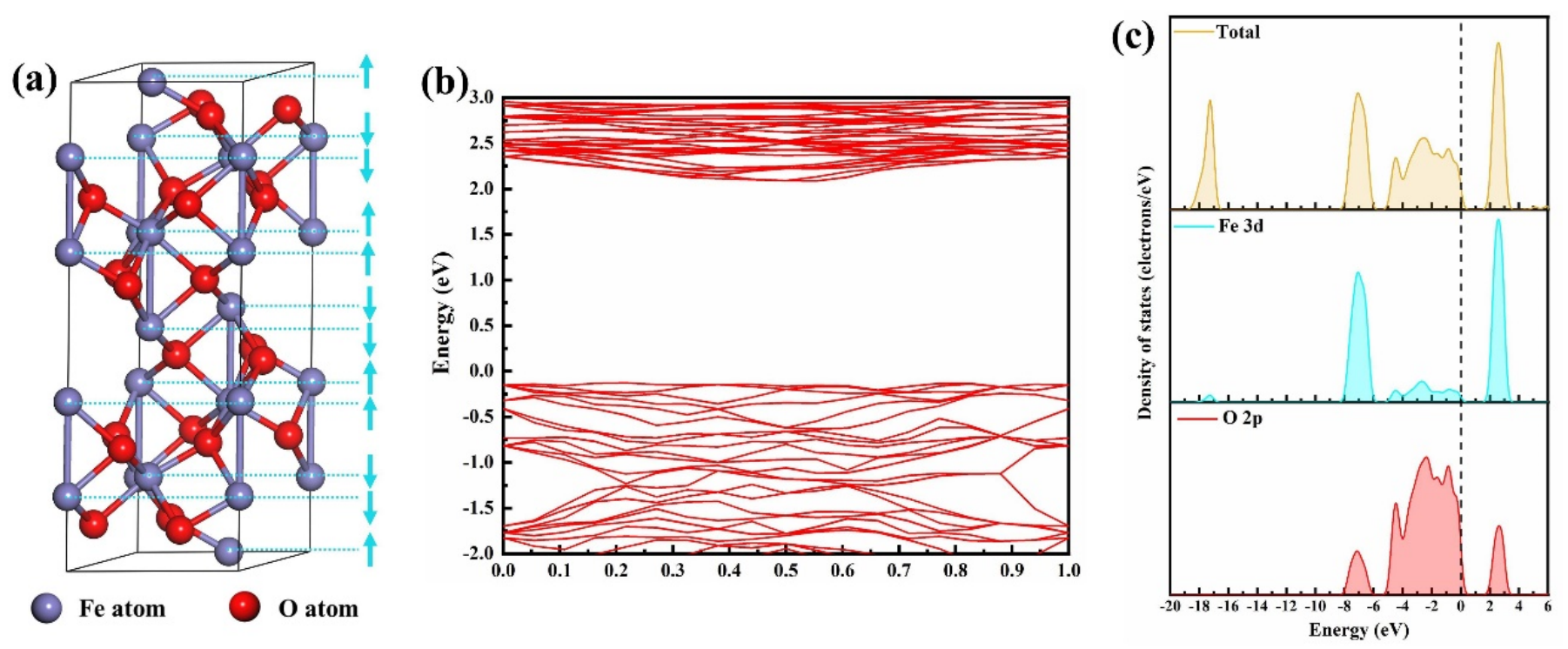

Figure 1. (a) The crystal structure and spin arrangement of $\alpha-\mathrm{Fe}_{2} \mathrm{O}_{3} ;(\mathbf{b})$ the band structure of $\alpha-\mathrm{Fe}_{2} \mathrm{O}_{3}$; and (c) the DOS and PDOS analysis of $\alpha-\mathrm{Fe}_{2} \mathrm{O}_{3}$.

The positive or negative adsorption energy and the adsorption distance reflect the stability of the structure after adsorption [36]. If the adsorption energy is negative, the adsorption distance decreases, indicating that the process is the release of heat, and the structure is more stable after adsorption. Otherwise, the adsorption distance increases, indicating that the process is the absorption of heat, and the structure is not stable after adsorption [37]. In order to analyze the stability of gas molecules at different adsorption sites, the adsorption energy $E_{a d s}$ of each model is calculated according to the following formula:

$$
E_{\text {ads }}=E_{\text {molecule/slab }}-E_{\text {molecule }}-E_{\text {slab }}
$$

where $E_{\text {molecule/slab }}$ is the total energy of the system after adsorption, $E_{\text {molecule }}$ is the energy of the adsorbed free gas molecules, and $E_{\text {slab }}$ is the energy of the substrate before adsorption.

The charge difference density reflects the charge transfer in different regions. The expression is:

$$
\Delta \rho=\rho_{\text {molecule } / \text { slab }}-\rho_{\text {slab }}-\rho_{\text {molecule }}
$$

In the formula, $\rho_{\text {molecule/slab }}, \rho_{\text {slab }}$, and $\rho_{\text {molecule }}$ represent the total charge density of the system after adsorption, the charge density of the substrate before adsorption, and the charge density of free gas molecules, respectively. Mulliken charge population analysis is used to examine the charge transfer before and after gas adsorption on the surface [38]. A negative number represents an electron, and a positive number indicates a loss of electron.

\subsection{Models}

The optimized crystal cell of $\alpha-\mathrm{Fe}_{2} \mathrm{O}_{3}$ is shown in Figure 1a. It has a space group crystal structure of $\mathrm{R}-3 \mathrm{C}$ and contains 12 iron atoms and 18 oxygen atoms. The lattice 
parameters of the cell are $a=b=5.18^{\circ}, c=14.11^{\circ}, \alpha=\beta=90^{\circ}$, and $\gamma=120^{\circ}$, which are in good agreement with the experimental values $\left(a=b=5.04^{\circ}, c=13.75^{\circ}, \alpha=\beta=90^{\circ}\right.$, and $\gamma=120^{\circ}$ ). It shows that the model is reliable [39]. Referring to previous studies, the $\mathrm{Fe}-\mathrm{O}_{3}-\mathrm{Fe}$ termination of (001) surface is the most stable surface termination $[10,40,41]$. Therefore, on the basis of the optimized $\alpha-\mathrm{Fe}_{2} \mathrm{O}_{3}$ cell, a 12-layer $\mathrm{p}(2 \times 2)$ supercell was constructed and cut out (001) surface. To avoid interaction during continuous plate weeks, a vacuum layer of $15 \AA$ was added in the z direction to build the slab model, as shown in Figure 2a. The six layers of atoms at the bottom are fixed to simulate the bulk phase, and the six layers of the surface are completely relaxed in the process of calculation. However, previous studies have shown that the outermost atomic layer of the relaxation 4 layers is sufficient to obtain sufficient convergence results on the $\alpha-\mathrm{Fe}_{2} \mathrm{O}_{3}(001)$ surface [42]. It is well known that crystal defects do not have a negligible effect on molecular adsorption. Oxygen vacancy defects easily occur on the surface of $\alpha-\mathrm{Fe}_{2} \mathrm{O}_{3}$ [13]. The vacancy $\alpha-\mathrm{Fe}_{2} \mathrm{O}_{3}(001)$ surface model is obtained by removing an oxygen atom on the surface. Based on this, we constructed the $\alpha-\mathrm{Fe}_{2} \mathrm{O}_{3}(001)$ surface with and without vacancy at the same time. The adsorption models of three sulphide gas molecules at five symmetric adsorption sites $(\mathrm{O}$ top site, Fe top site, Bridge site, Hollow site, and vacancy) are shown in Figure 1b,c.

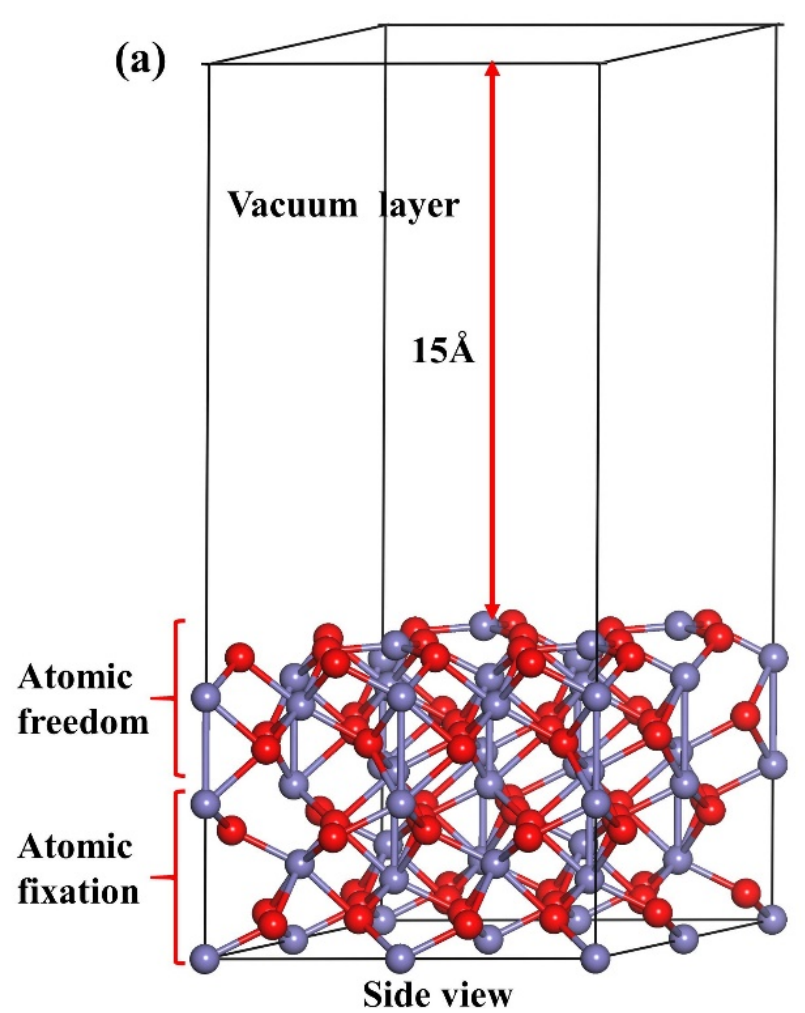

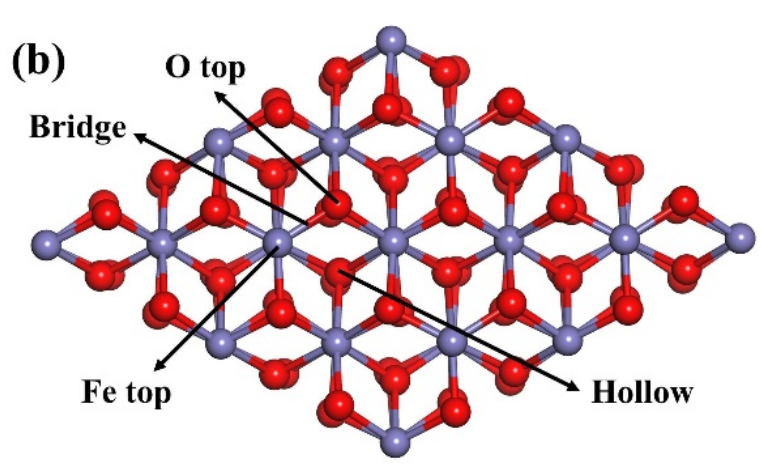

Top view

(c)

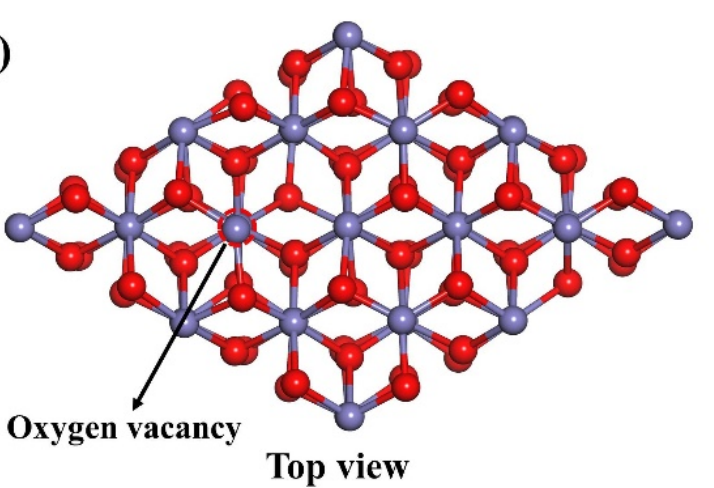

Figure 2. (a) The geometrically optimized slab model of $\alpha-\mathrm{Fe}_{2} \mathrm{O}_{3}(001)$ surface; (b) the adsorption site on pure $\alpha$-Fe $\mathrm{O}_{3}(001)$ surface; and (c) the adsorption site of oxygen vacancy $\alpha-\mathrm{Fe}_{2} \mathrm{O}_{3}(001)$ surface.

$\mathrm{H}_{2} \mathrm{~S}, \mathrm{COS}$, and $\mathrm{CH}_{3} \mathrm{SH}$ molecules are put into a three-dimensional cubic lattice with an edge length of $10 \AA$, and have been geometrically optimized without restriction. The k-point sampling in Brillouin zone is set to $1 \times 1 \times 1$. The geometrically optimized configuration is shown in Figure 3. The values of all structures are consistent with the previous research or experimental values. The reliability of the calculation is guaranteed. 

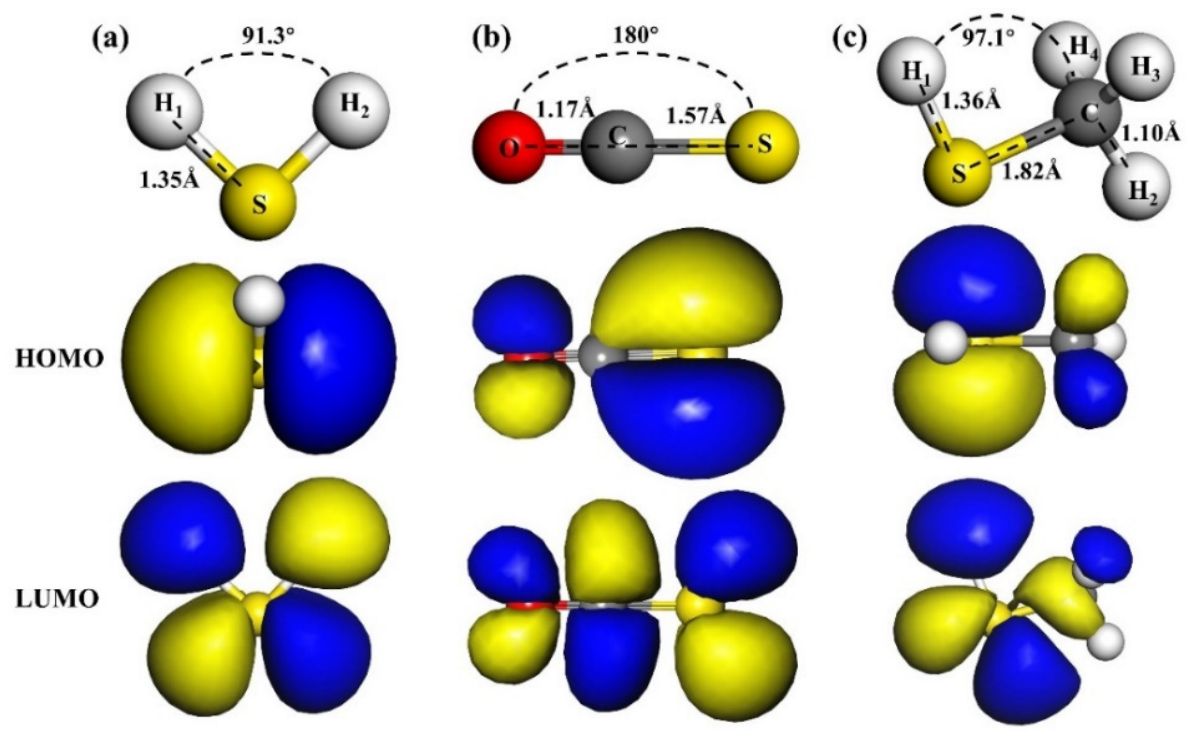

Figure 3. The geometrically optimized (a) $\mathrm{H}_{2} \mathrm{~S}$, (b) $\mathrm{COS}$, and (c) $\mathrm{CH}_{3} \mathrm{SH}$ molecules, and their HOMO (Highest Energy Occupied Orbital) and LUMO (Lowest Energy Empty Orbital).

\section{Results and Discussion}

Using the HOMO and LUMO in the electron cloud around molecules [43,44], we analyzed the electronic properties of $\mathrm{H}_{2} \mathrm{~S} \mathrm{COS}$ and $\mathrm{CH}_{3} \mathrm{SH}$, as shown in Figure 3. We found that the HOMO orbitals of the three molecules were concentrated on the $\mathrm{S}$ atoms, indicating that the $S$ atoms in the molecules more readily give electrons in the adsorption process.

\section{1. $\mathrm{H}_{2} \mathrm{~S}$ Adsorption}

The optimized $\mathrm{H}_{2} \mathrm{~S}$ molecules were placed near several adsorption sites described above in a parallel or vertical manner. As shown in Figure 4, several stable adsorption configurations were obtained through geometric optimization of high-precision criteria.

The corresponding adsorption energy and the geometric parameters of the stable adsorption configuration are listed in Table 1.

In $\mathrm{A} 1$ and $\mathrm{A} 2$ configurations, although the specific spatial position and direction of $\mathrm{H}_{2} \mathrm{~S}$ molecules are different, the whole molecule was adsorbed on the top of the terminal Fe atom by a $S$ atom in an inclined way. The adsorption distance between the $S$ atom and the Fe atom is $2.59 \AA$ and $2.57 \AA$, respectively, and the corresponding adsorption energy is about $-0.56 \mathrm{eV}$ and $-0.53 \mathrm{eV}$. By examining the different adsorption sites, it can be inferred that the adsorption sites of $\mathrm{H}_{2} \mathrm{~S}$ molecules on the $\alpha-\mathrm{Fe}_{2} \mathrm{O}_{3}(001)$ surface were mainly concentrated near the three-coordinated Fe atoms. The configuration shown in $\mathrm{A} 3$ and $\mathrm{A} 4$ is that in which the $\mathrm{H}_{2} \mathrm{~S}$ molecule was adsorbed on the Fe atom on the surface with oxygen vacancy. The bond angle of $\mathrm{H}_{2} \mathrm{~S}$ molecule in A3 increased slightly to 93.0 compared with that before adsorption, indicating that $\mathrm{H}_{2} \mathrm{~S}$ was activated after adsorption. That is, this reaction belongs to stable chemical adsorption. For the A4 case, $\mathrm{H}_{2} \mathrm{~S}$ molecules were dissociated and adsorbed, and one of the $\mathrm{S}-\mathrm{H}$ bonds was broken due to the influence of adsorption. The $\mathrm{H}$ atom was trapped by the $\mathrm{O}$ atom in the attachment. SH was firmly adsorbed on the Fe atom. The adsorption energy was $-1.53 \mathrm{eV}$ and the adsorption distance was $2.34 \AA$. Compared with the adsorption on the surface without vacancy, the absolute value of adsorption energy on the vacancy surface was larger and the adsorption effect was stronger. 


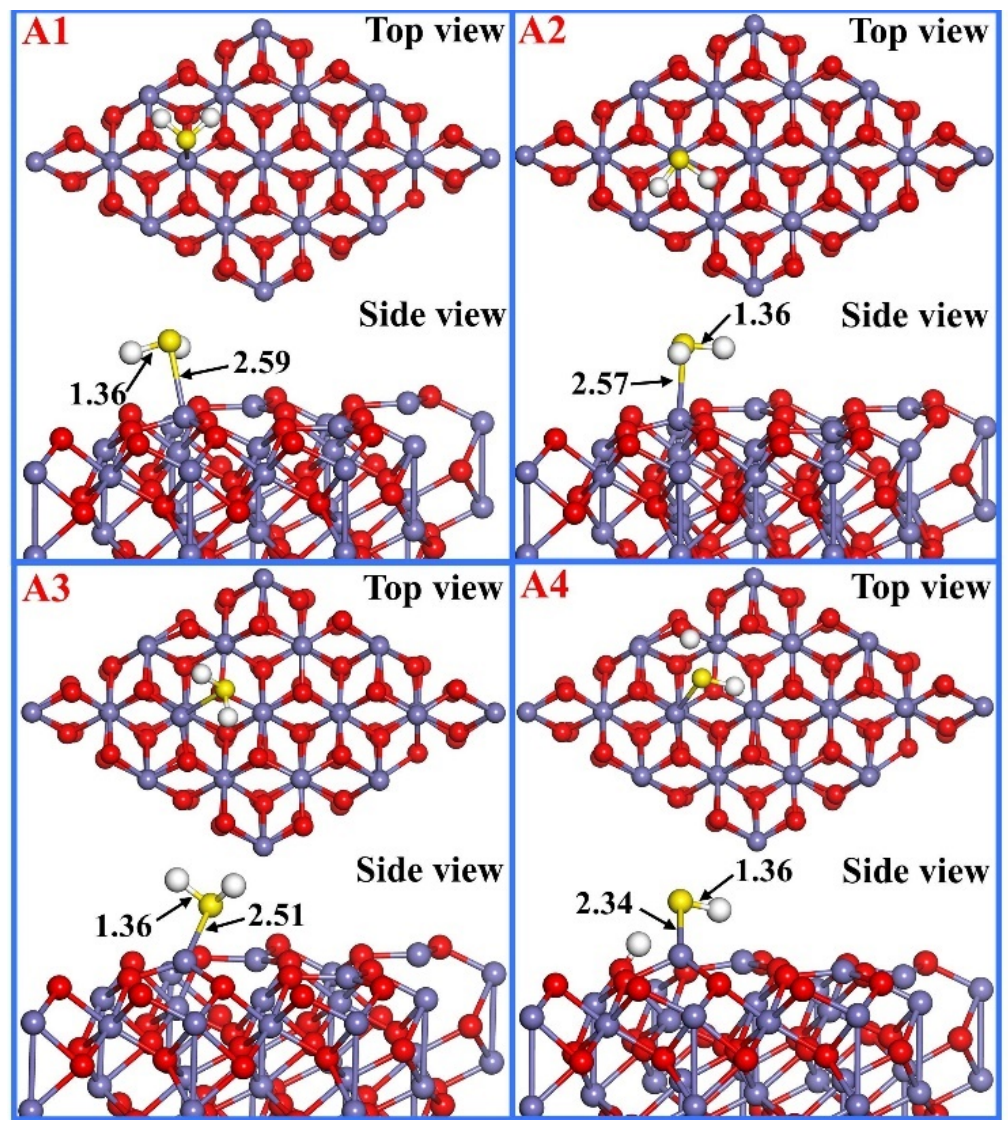

Figure 4. The stable adsorption configuration of $\mathrm{H}_{2} \mathrm{~S}$ molecules on pure $\alpha-\mathrm{Fe}_{2} \mathrm{O}_{3}(001)$ surface (A1, A2); and the stable adsorption configuration of $\mathrm{H}_{2} \mathrm{~S}$ molecules on vacancy $\alpha-\mathrm{Fe}_{2} \mathrm{O}_{3}(001)$ surface (A3, A4). The unit of number is $\AA$.

Table 1. The adsorption energy and characteristic parameters of adsorption configuration of $\mathrm{H}_{2} \mathrm{~S}$ on the $\alpha-\mathrm{Fe}_{2} \mathrm{O}_{3}(001)$ Surface.

\begin{tabular}{|c|c|c|c|c|c|c|}
\hline $\begin{array}{l}\text { Adsorption } \\
\text { Configuration }\end{array}$ & \multicolumn{2}{|c|}{ Bond Length (Å) } & \multicolumn{2}{|c|}{ Bond Angle $\left({ }^{\circ}\right)$} & \multirow{2}{*}{$\begin{array}{c}E_{a d s}(\mathrm{eV}) \\
-0.56\end{array}$} & \multirow{2}{*}{$\begin{array}{r}d(\AA) \\
2.59\end{array}$} \\
\hline A1 & $\begin{array}{l}\text { S-H } \\
\text { S-H } \\
2\end{array}$ & $\begin{array}{l}1.36 \\
1.36\end{array}$ & $\mathrm{H}_{1}-\mathrm{S}-\mathrm{H}_{2}$ & 91.3 & & \\
\hline $\mathrm{A} 2$ & $\begin{array}{l}\mathrm{S}-\mathrm{H}_{1} \\
\mathrm{~S}-\mathrm{H}_{2}\end{array}$ & $\begin{array}{l}1.36 \\
1.36\end{array}$ & $\mathrm{H}_{1}-\mathrm{S}-\mathrm{H}_{2}$ & 91.9 & -0.53 & 2.57 \\
\hline A3 & $\begin{array}{l}\text { S-H } H_{1} \\
\text { S-H }{ }_{2}\end{array}$ & $\begin{array}{l}1.36 \\
1.36\end{array}$ & $\mathrm{H}_{1}-\mathrm{S}-\mathrm{H}_{2}$ & 93.0 & -0.64 & 2.51 \\
\hline A4 & - & - & - & - & -1.53 & - \\
\hline
\end{tabular}

The PDOS of the $\mathrm{S}$ atom in $\mathrm{H}_{2} \mathrm{~S}$ molecule before adsorption is shown in Figure 5. The DOS of the $S$ atom was mainly contributed by $3 p$ orbitals, and 3 s and $3 p$ orbitals showed discrete sharp peaks, indicating that the localization of electrons is very strong and the corresponding energy bands are relatively narrow.

Figure 6a shows the PDOS of Fe atoms on the $\alpha-\mathrm{Fe}_{2} \mathrm{O}_{3}(001)$ surface before adsorption. The TDOS of Fe was mainly contributed by its 3D orbital, showing an obvious peak, indicating that the d-electron phase is localized. There is almost no symmetry in the spinup and spin-down PDOS, indicating that the Fe atom has magnetism. Vacancy defects will affect the PDOS of Fe atoms near the surface. Due to the absence of the coordinated O atom, the highly localized $3 \mathrm{~d}$ orbital peak of Fe atom split, several small peaks appeared, 
and the energy level shifted slightly. In Figure $6 b$, when $\mathrm{H}_{2} \mathrm{~S}$ was adsorbed on the pure $\alpha-\mathrm{Fe}_{2} \mathrm{O}_{3}(001)$ surface, the $3 p$ orbital of the $\mathrm{S}$ atom broadened in the $-6 \sim-1 \mathrm{eV}$ energy range. The contribution of the upper and lower spin states of the $S$ atom was different, which is related to a certain magnetization. The PDOS of the interacting Fe atom changed slightly compared with that before adsorption, and the strong magnetic property of the Fe-3d band did not change with the adsorption of $\mathrm{H}_{2} \mathrm{~S}$. It shows that there was a weak interaction between them. When $\mathrm{H}_{2} \mathrm{~S}$ was adsorbed on the Fe atom of the vacancy $\alpha-\mathrm{Fe}_{2} \mathrm{O}_{3}(001)$ surface, the $3 p$ orbital of the $S$ atom broadened in the $-7 \sim 0 \mathrm{eV}$ energy range, and hybridized with the $3 \mathrm{~d}$ orbital of the Fe atom at the adsorption site, and there was obvious resonance. The peak shape of the Fe atom in the vacancy changed obviously after adsorption. It shows that the adsorption between them is strong. This is consistent with the results of adsorption energy.

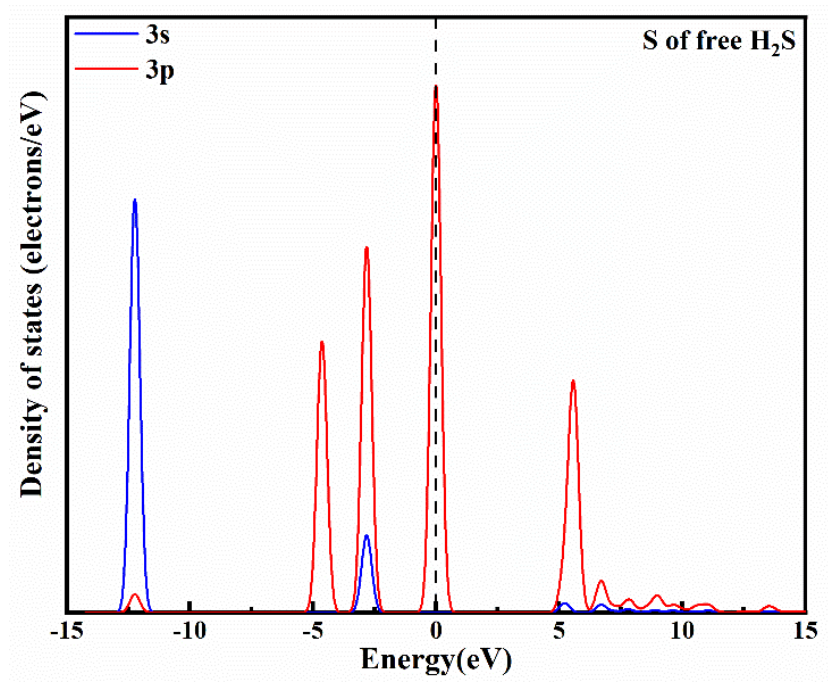

Figure 5. The PDOS of $\mathrm{S}$ atom in free $\mathrm{H}_{2} \mathrm{~S}$ molecule.
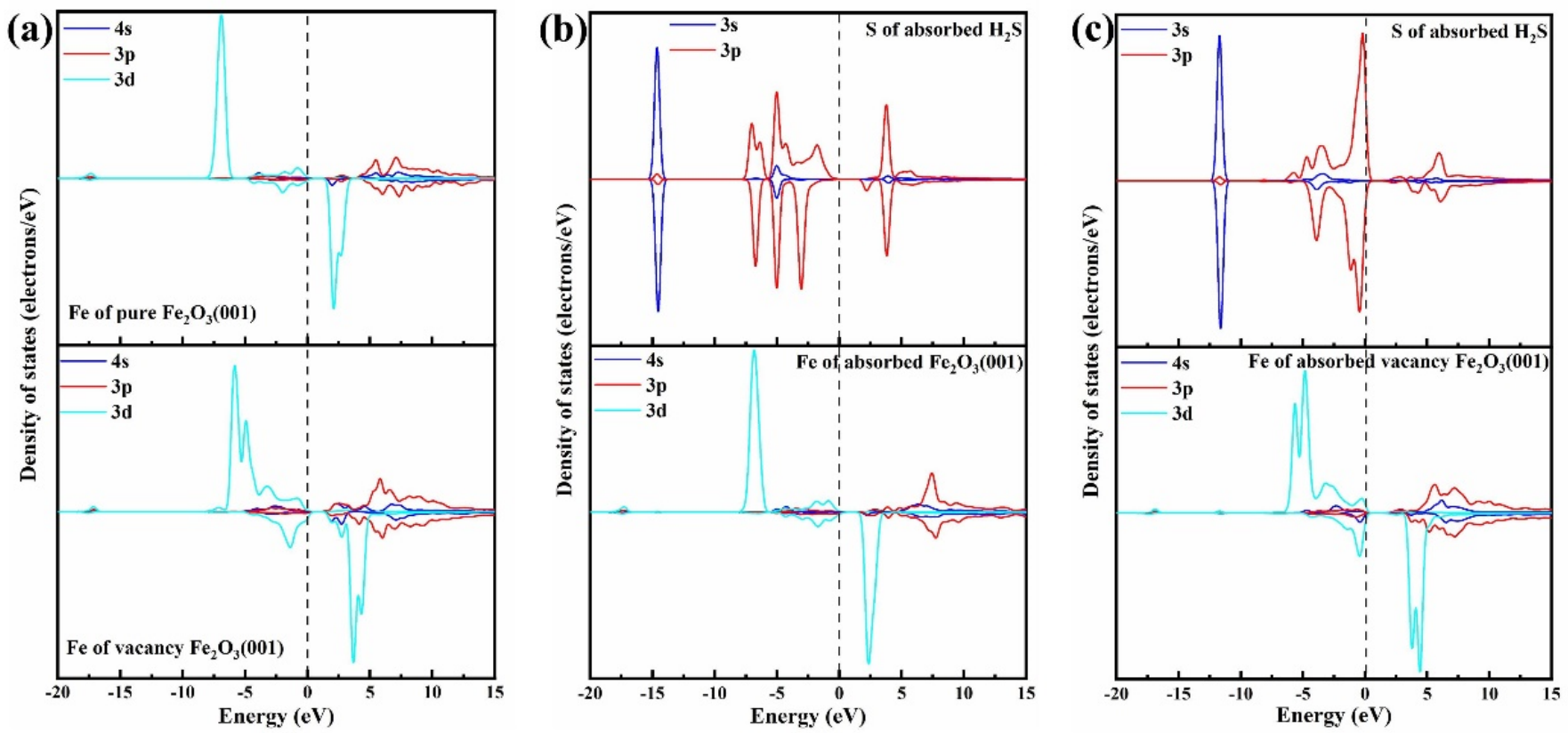

Figure 6. (a) The PDOS of Fe atoms on the pure and vacant $\alpha-\mathrm{Fe}_{2} \mathrm{O}_{3}(001)$ surface before adsorption; (b) the PDOS of pure $\alpha-\mathrm{Fe}_{2} \mathrm{O}_{3}(001)$ surface of $\mathrm{Fe}$ atom and $\mathrm{S}$ atom of $\mathrm{H}_{2} \mathrm{~S}$ after adsorption; and (c) the PDOS of Fe atom and $\mathrm{S}$ atom of $\mathrm{H}_{2} \mathrm{~S}$ on the surface of the adsorbed vacancy $\alpha-\mathrm{Fe}_{2} \mathrm{O}_{3}(001)$. 
Figure 7a,b shows the charge difference density of A2 configuration. As can be seen, the electron accumulation region of $\alpha-\mathrm{Fe}_{2} \mathrm{O}_{3}$ was mainly concentrated near the $\mathrm{O}$ atom and the charge depletion region near the Fe atom. Combined with the results of the Mulliken charge population analysis shown in Table 2, the adsorption of $\mathrm{H}_{2} \mathrm{~S}$ molecules did not lead to obvious charge redistribution, indicating that the adsorption of $\mathrm{H}_{2} \mathrm{~S}$ molecules with the pure $\alpha-\mathrm{Fe}_{2} \mathrm{O}_{3}(001)$ surface was weak. In the A4 configuration, as shown in Figure $7 \mathrm{c}, \mathrm{d}$, the Fe atoms at the adsorption site lost some electrons, and a large number of charges gathered between the S-Fe to form chemical bonds. The dissociated $\mathrm{SH}$ obtained 0.47 e from the $\alpha-\mathrm{Fe}_{2} \mathrm{O}_{3}(001)$ surface indicated that there was a strong interaction between them, resulting in charge rearrangement.

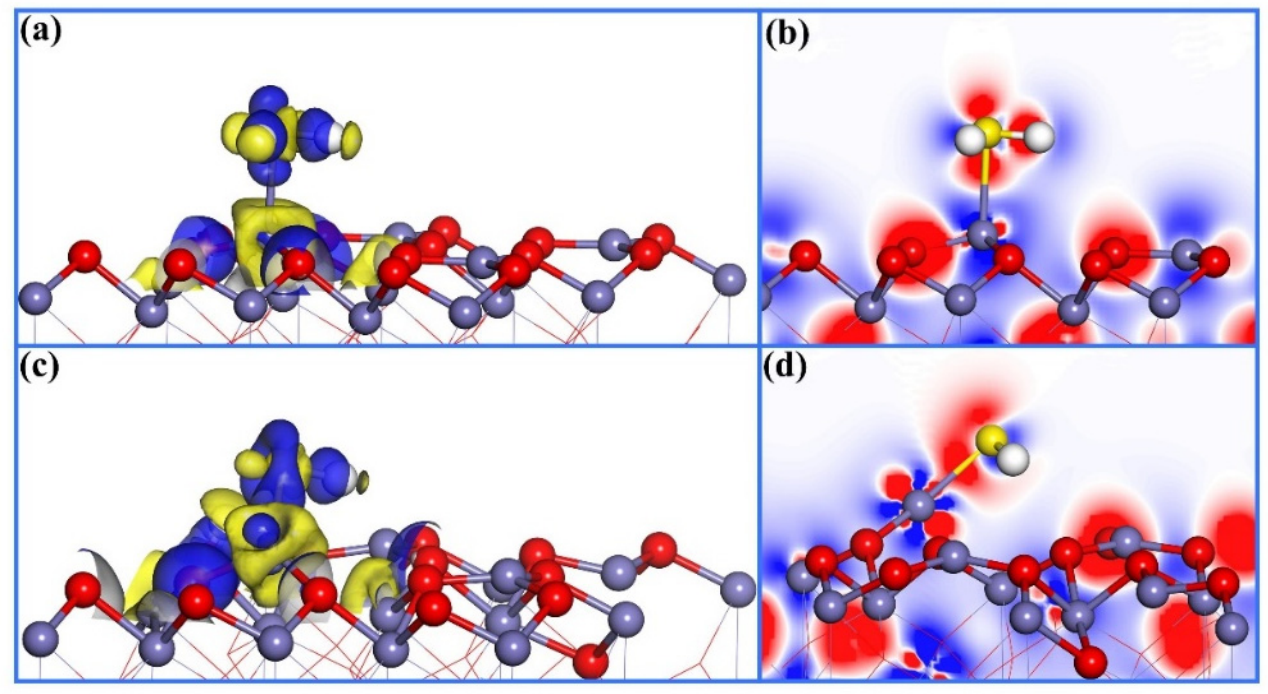

Figure 7. The Mulliken charge population analysis of $\mathrm{H}_{2} \mathrm{~S}$ adsorption on the $\alpha-\mathrm{Fe}_{2} \mathrm{O}_{3}(001)$ surface. (a) Three dimensional drawing of the Mulliken charge population for A2 configuration; (b) Two dimensional drawing of the Mulliken charge population for A2 configuration; (c) Three dimensional drawing of the Mulliken charge population for A4 configuration; (d) Two dimensional drawing of the Mulliken charge population for A4 configuration.

Table 2. The Mulliken charge population analysis of $\mathrm{H}_{2} \mathrm{~S}$ adsorption on the $\alpha-\mathrm{Fe}_{2} \mathrm{O}_{3}(001)$ surface.

\begin{tabular}{cccc}
\hline $\begin{array}{c}\text { Adsorption } \\
\text { Configuration }\end{array}$ & \multicolumn{2}{c}{ Mulliken Charge (e) } & Q (e) \\
\hline \multirow{2}{*}{$\mathrm{A} 2$} & $\mathrm{~S}$ & -0.25 & 0.09 \\
& $\mathrm{H}_{1}$ & 0.17 & \\
\hline \multirow{2}{*}{$\mathrm{A} 4$} & $\mathrm{H}_{2}$ & 0.17 & -0.47 \\
& $\mathrm{~S}$ & -0.54 & \\
\hline
\end{tabular}

\subsection{COS Adsorption}

All possible surface adsorption sites and the straight-line adsorption of COS molecules were taken into account. Due to the asymmetric structure of COS molecules, the adsorption processes of parallel, vertical, and $\mathrm{S}$ atoms toward the surface, and $\mathrm{O}$ atoms toward the surface were investigated. After geometric optimization, several configurations, shown in Figure 8, were finally obtained, which are recorded as B1-B4. As shown in Table 3, the adsorption energy of each configuration was positive, indicating that COS molecules could not be adsorbed on the surface of $\alpha-\mathrm{Fe}_{2} \mathrm{O}_{3}$ spontaneously. The $\mathrm{C}$ atom of the COS molecule was connected to a $\mathrm{S}$ atom by double bond and an $\mathrm{O}$ atom, and there was a stable $\pi$ bond. Therefore, the fact that COS molecules were not spontaneously adsorbed on the surface of $\alpha-\mathrm{Fe}_{2} \mathrm{O}_{3}$ may be related to the stable chemical properties of the molecules themselves. 


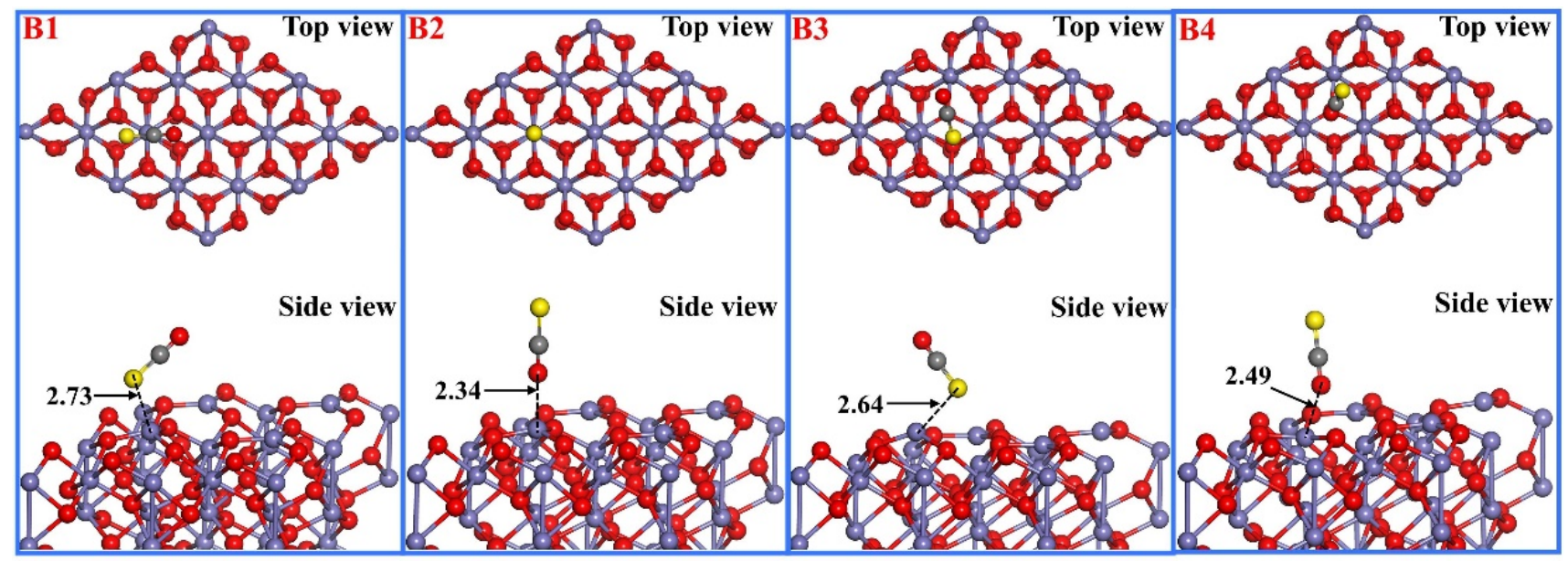

Figure 8. The stable adsorption configurations (B1,B2) of COS molecules on a pure $\alpha-\mathrm{Fe}_{2} \mathrm{O}_{3}(001)$ surface; the stable adsorption configurations (B3,B4) of COS molecules on the vacancy $\alpha-\mathrm{Fe}_{2} \mathrm{O}_{3}(001)$ surface (the unit of number is $\AA$ ).

Table 3. The adsorption energy and adsorption configuration characteristic parameters of COS on the $\alpha-\mathrm{Fe}_{2} \mathrm{O}_{3}(001)$ surface.

\begin{tabular}{|c|c|c|c|c|c|c|}
\hline $\begin{array}{l}\text { Adsorption } \\
\text { System }\end{array}$ & Bonc & $(\AA ̊)$ & Bond & le $\left(^{\circ}\right)$ & $E_{a d s}(\mathrm{eV})$ & $d(\AA)$ \\
\hline B1 & $\begin{array}{l}\mathrm{C}-\mathrm{O} \\
\mathrm{C}-\mathrm{S}\end{array}$ & $\begin{array}{l}1.17 \\
1.57\end{array}$ & $\mathrm{~S}-\mathrm{C}-\mathrm{O}$ & 179.6 & 0.36 & 2.73 \\
\hline B2 & $\begin{array}{l}\mathrm{C}-\mathrm{O} \\
\mathrm{C}-\mathrm{S}\end{array}$ & $\begin{array}{l}1.17 \\
1.56\end{array}$ & $\mathrm{~S}-\mathrm{C}-\mathrm{O}$ & 179.9 & 0.44 & 2.34 \\
\hline B3 & $\begin{array}{l}\mathrm{C}-\mathrm{O} \\
\mathrm{C}-\mathrm{S}\end{array}$ & $\begin{array}{l}1.17 \\
1.59\end{array}$ & $\mathrm{~S}-\mathrm{C}-\mathrm{O}$ & 179.7 & 0.22 & 2.64 \\
\hline B4 & $\begin{array}{l}\text { C-O } \\
\text { C-S }\end{array}$ & $\begin{array}{l}1.17 \\
1.56\end{array}$ & $\mathrm{~S}-\mathrm{C}-\mathrm{O}$ & 179.3 & 0.42 & 2.49 \\
\hline
\end{tabular}

\section{3. $\mathrm{CH}_{3} \mathrm{SH}$ Adsorption}

As shown in Figure 9, two stable adsorption configurations of $\mathrm{CH}_{3} \mathrm{SH}$ molecules were obtained, named as $\mathrm{C} 1$ and $\mathrm{C} 2$. The characteristic parameters of each adsorption configuration are listed in Table 4 . In the $\mathrm{C} 1$ configuration, the $\mathrm{CH}_{3} \mathrm{SH}$ molecule was adsorbed on the Fe top site of the pure $\alpha-\mathrm{Fe}_{2} \mathrm{O}_{3}(001)$ surface in an inclined posture with an adsorption distance of $2.52 \AA$ and adsorption energy of $-0.50 \mathrm{eV}$. The bond angle of H1-S-C was larger than that of free molecules, and other structural parameters were almost unchanged. This suggests that there is a weak interaction between $\mathrm{CH}_{3} \mathrm{SH}$ molecule and the pure $\alpha-\mathrm{Fe}_{2} \mathrm{O}_{3}(001)$ surface. The $\mathrm{C} 2$ of Figure 9 shows the dissociative adsorption configuration of $\mathrm{CH}_{3} \mathrm{SH}$ molecules. The $\mathrm{S}-\mathrm{H}$ bond was broken during the adsorption process, and the $\mathrm{H}$ atom was adsorbed on the nearby tri-coordinated $\mathrm{O}$ atom. $\mathrm{CH}_{3} \mathrm{~S}$ was adsorbed on the vacancy defect site with an adsorption energy of $-1.40 \mathrm{eV}$ and an adsorption distance of $2.34 \AA$. It is worth noting that the Fe atoms on the surface of $\alpha-\mathrm{Fe}_{2} \mathrm{O}_{3}(001)$ at the adsorption site relaxed and protruded slightly from the adsorption molecules after $\mathrm{CH}_{3} \mathrm{SH}$ adsorption. We found that the relaxation degree of the Fe atoms on the defective surface was greater than that on the surface without vacancy. 


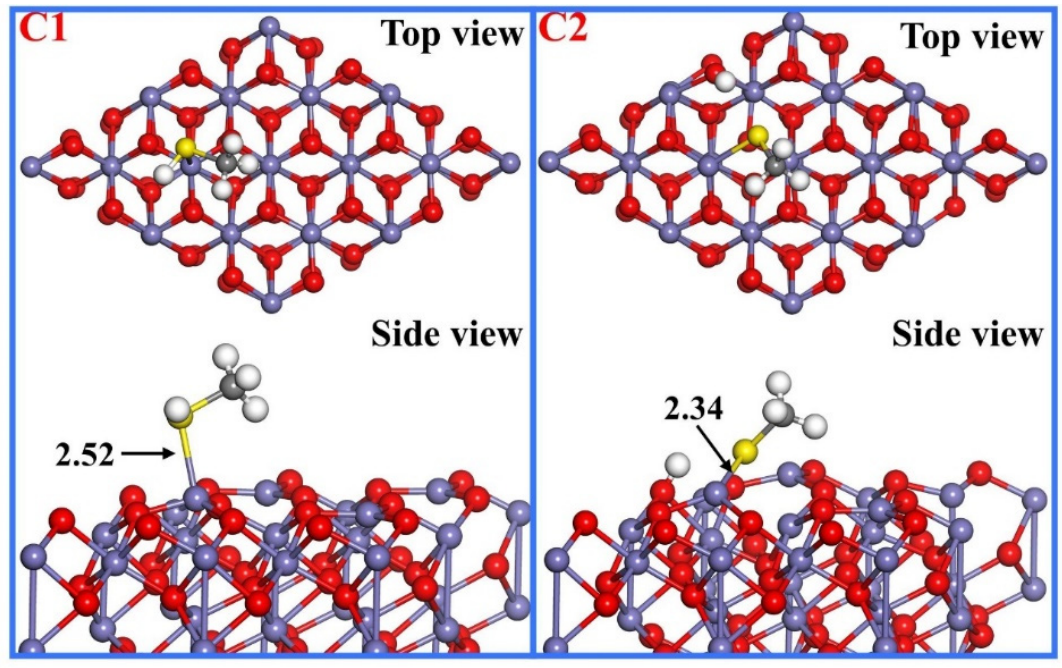

Figure 9. The stable adsorption configuration $\mathrm{C} 1$ of $\mathrm{CH}_{3} \mathrm{SH}$ molecules on the pure $\alpha-\mathrm{Fe}_{2} \mathrm{O}_{3}(001)$ surface; the stable adsorption configuration $\mathrm{C} 2$ of $\mathrm{SH}$ molecule on the vacancy $\alpha-\mathrm{Fe}_{2} \mathrm{O}_{3}(001)$ surface (the unit of number is $\AA$ ).

Table 4. The adsorption energy and adsorption configuration characteristic parameters of $\mathrm{CH}_{3} \mathrm{SH}$ on the $\alpha-\mathrm{Fe}_{2} \mathrm{O}_{3}$ surface.

\begin{tabular}{|c|c|c|c|c|c|c|}
\hline $\begin{array}{l}\text { Adsorption } \\
\text { Configuration }\end{array}$ & \multicolumn{2}{|c|}{ Bond Length $(\AA ̊)$} & \multicolumn{2}{|c|}{ Bond Angle $\left({ }^{\circ}\right)$} & $E_{a d s}(\mathrm{eV})$ & $d(\AA)$ \\
\hline $\mathrm{C} 1$ & $\begin{array}{c}\text { S- } \mathrm{H}_{1} \\
\text { S-C } \\
\text { C- } \mathrm{H}_{2} \\
\text { C- } \mathrm{H}_{3} \\
\text { C- } \mathrm{H}_{4}\end{array}$ & $\begin{array}{l}1.36 \\
1.83 \\
1.10 \\
1.10 \\
1.10\end{array}$ & $\begin{array}{l}\mathrm{H}_{1}-\mathrm{S}-\mathrm{C} \\
\mathrm{S}-\mathrm{C}-\mathrm{H}_{2} \\
\mathrm{~S}-\mathrm{C}-\mathrm{H}_{3} \\
\text { S-C-H }\end{array}$ & $\begin{array}{c}98.2 \\
108.7 \\
109.9 \\
108.0\end{array}$ & -0.50 & 2.52 \\
\hline C2 & $\begin{array}{c}\text { S- } \mathrm{H}_{1} \\
\text { S-C } \\
\text { C- } \mathrm{H}_{2} \\
\text { C- } \mathrm{H}_{3} \\
\mathrm{C}-\mathrm{H}_{4}\end{array}$ & $\begin{array}{c}- \\
1.84 \\
1.10 \\
1.10 \\
1.10\end{array}$ & $\begin{array}{l}\mathrm{H}_{1}-\mathrm{S}-\mathrm{C} \\
\mathrm{S}-\mathrm{C}-\mathrm{H}_{2} \\
\text { S-C- } \mathrm{H}_{3} \\
\text { S-C-H }\end{array}$ & $\begin{array}{c}- \\
112.1 \\
107.3 \\
108.9\end{array}$ & -1.40 & 2.34 \\
\hline
\end{tabular}

The PDOS of the $\mathrm{S}$ atom in the free $\mathrm{CH}_{3} \mathrm{SH}$ molecule is shown in Figure 10a. Figure 10b,c shows the PDOS of the $\mathrm{S}$ atom after adsorption and the Fe atom on the surface with and without vacancy, respectively. On the pure $\alpha-\mathrm{Fe}_{2} \mathrm{O}_{3}(001)$ surface, the 3 s orbital of the $\mathrm{S}$ atom changed slightly, but still maintained a discrete energy level. The $3 p$ orbital of the $S$ atom broadened in the $-7.7 \sim 0 \mathrm{eV}$ energy region. At the same time, the peak shape and number of electron orbitals of the Fe atom did not change obviously. According to Figure 10d,e and Table 5, there was almost no electron exchange and transfer, which indicates that the adsorption of $\mathrm{CH}_{3} \mathrm{SH}$ molecules on the pure $\alpha-\mathrm{Fe}_{2} \mathrm{O}_{3}(001)$ surface was very weak. In Figure 10c, the $3 p$ orbitals of the $S$ atoms were broadened in the $-7.7 \sim 0 \mathrm{eV}$ and $1.7 \sim 6.3 \mathrm{eV}$ energy regions. The $3 \mathrm{~d}$ orbital peak shape of the Fe atom changed and there was a hybrid conjugation between the $3 p$ orbital of the $S$ atom and the $3 \mathrm{~d}$ orbital of the Fe atom. According to Figure 10f,g, it is obvious that there was a charge enrichment region between the adsorbed molecule and the surface. The surface obtained $0.42 \mathrm{e}$ from the dissociated and adsorbed $\mathrm{H}$ atom, and the Mulliken charge population of $\mathrm{CH}_{3} \mathrm{~S}$ was $-0.40 \mathrm{e}$, indicating that some electrons were captured from the surface. There was an overlap between the electron loss region and the electron enrichment region in the figure, indicating that the electrons were rearranged, and part of the electrons migrated to form a chemical bond between the adsorbed molecule and the surface. That is, $\mathrm{CH}_{3} \mathrm{SH}$ chemisorption occured on the vacancy $\alpha-\mathrm{Fe}_{2} \mathrm{O}_{3}(001)$ surface and the adsorption effect was strong. 

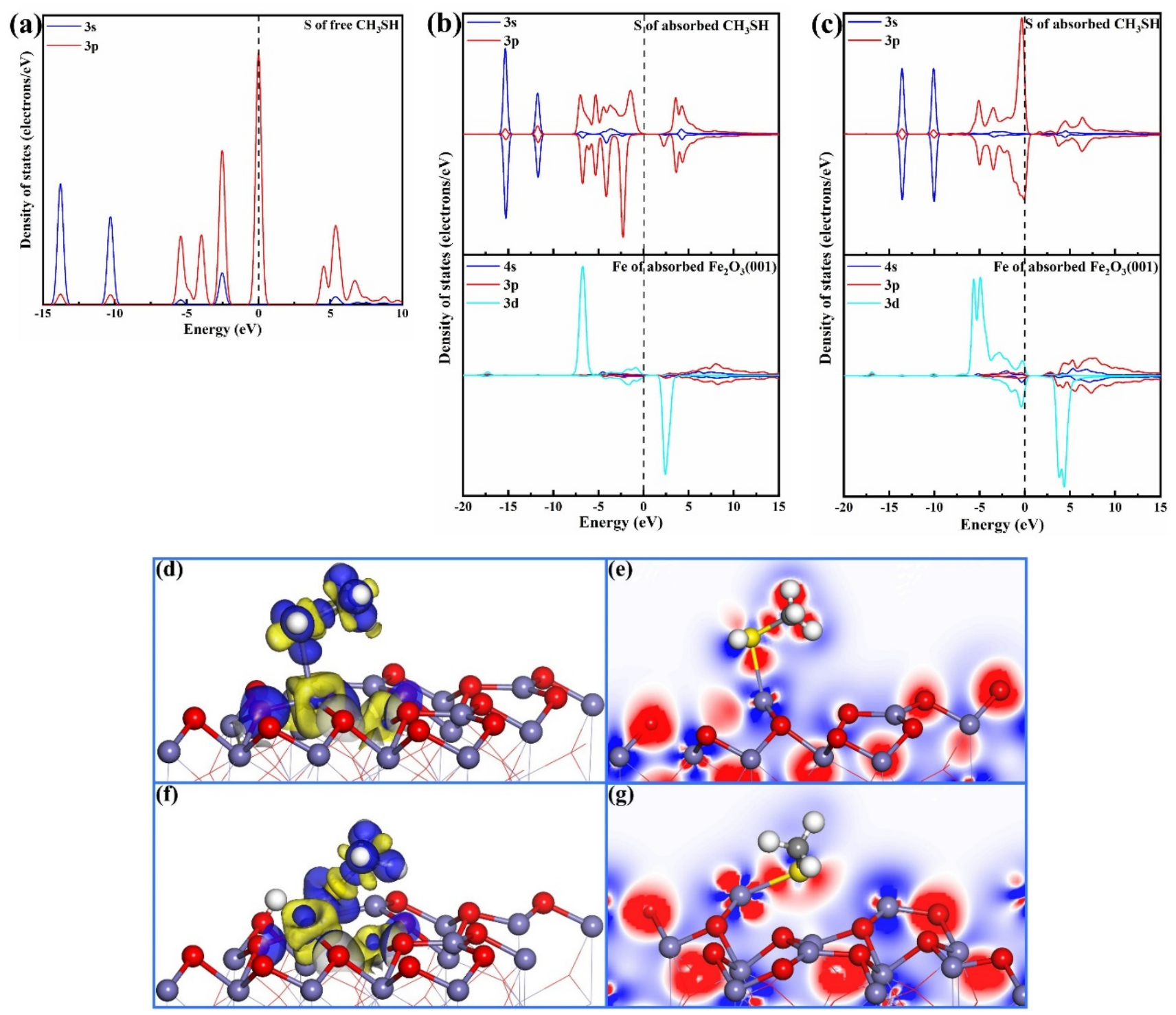

Figure 10. (a) The PDOS of the $\mathrm{S}$ atom in a free $\mathrm{CH}_{3} \mathrm{SH}$ molecule; (b) the PDOS of pure $\alpha-\mathrm{Fe}_{2} \mathrm{O}_{3}(001)$ surface Fe atom and $\mathrm{S}$ atom of $\mathrm{CH}_{3} \mathrm{SH}$ after adsorption; (c) the PDOS of the Fe atom and the $\mathrm{S}$ atom of $\mathrm{CH}_{3} \mathrm{SH}$ atom on the surface of the vacancy $\alpha-\mathrm{Fe}_{2} \mathrm{O}_{3}(001)$ after adsorption; (d,e) the charge difference density of $\mathrm{CH}_{3} \mathrm{SH}$ molecules adsorbed on the pure $\alpha-\mathrm{Fe}_{2} \mathrm{O}_{3}(001)$ surface; and $(\mathbf{f}, \mathbf{g})$ the charge difference density of $\mathrm{CH}_{3} \mathrm{SH}$ molecules adsorbed on the vacancy $\alpha-\mathrm{Fe}_{2} \mathrm{O}_{3}(001)$ surface.

Table 5. The Mulliken charge population analysis of $\mathrm{CH}_{3} \mathrm{SH}$ adsorbed on the $\alpha-\mathrm{Fe}_{2} \mathrm{O}_{3}(001)$ surface.

\begin{tabular}{cccc}
\hline Adsorption Configuration & \multicolumn{2}{c}{ Mulliken Charge (e) } & Q (e) \\
\hline \multirow{3}{*}{$\mathrm{C} 1$} & $\mathrm{~S}$ & -0.04 & \\
& $\mathrm{C}$ & -0.88 & \\
& $\mathrm{H}_{1}$ & 0.15 & 0.11 \\
& $\mathrm{H}_{2}$ & 0.31 & \\
$\mathrm{H}_{3}$ & 0.30 & \\
$\mathrm{H}_{4}$ & 0.27 & - \\
& $\mathrm{S}$ & -0.31 & \\
$\mathrm{C} 2$ & $\mathrm{C}$ & -0.83 & \\
& $\mathrm{H}_{1}$ & 0.42 & \\
& $\mathrm{H}_{2}$ & 0.28 & \\
& $\mathrm{H}_{3}$ & 0.24 & \\
& $\mathrm{H}_{4}$ & 0.22 &
\end{tabular}




\section{Conclusions}

In summary, the periodic DFT method was used to investigate the adsorption mechanism of $\mathrm{H}_{2} \mathrm{~S}, \mathrm{COS}$, and $\mathrm{CH}_{3} \mathrm{SH}$ gas molecules at different sites on the $\alpha-\mathrm{Fe}_{2} \mathrm{O}_{3}(001)$ surface. The exposed three-coordinate Fe atoms are the main active centers. The results show that $\mathrm{H}_{2} \mathrm{~S}$ and $\mathrm{CH}_{3} \mathrm{SH}$ are mainly adsorbed in the form of molecules at the Fe top site, and the adsorption energies are $-0.56 \mathrm{eV}$ and $-0.50 \mathrm{eV}$, respectively. Molecules can be adsorbed on Fe atoms in the form of molecules or dissociation in the oxygen vacancy. The oxygen vacancy can promote the dissociation of $\mathrm{H}_{2} \mathrm{~S}$ and $\mathrm{CH}_{3} \mathrm{SH}$ molecules, thus promoting the adsorption. The DOS results show that the electron orbitals of the dissociated states are more coincident, and the interaction is stronger. Charge differential density and Mulliken charge population analysis shows that charge exchange and transfer lead to the new surface chemical bonds formatted. However, no adsorption of COS molecules on the surface of $\alpha-\mathrm{Fe}_{2} \mathrm{O}_{3}$ was observed, which may be related to the inherent stable chemical properties of COS molecules.

Author Contributions: Data curation, L.Z., H.Z. and W.Z.; formal analysis, L.Z., H.Z. and W.Z.; funding acquisition, L.Z. and H.Z.; investigation, L.Z. and H.Z.; project administration, L.Z., H.Z. and W.Z. All authors have read and agreed to the published version of the manuscript.

Funding: This work was funded by China National Petroleum Corporation Science and Technology Project of "Research on New Methods of Natural Gas Quality Control and Energy Measurement Experiments and Operation Management" (2020D-5006-83).

Conflicts of Interest: The authors declare no conflict of interest. The funders had no role in the design of the study; in the collection, analyses, or interpretation of data; in the writing of the manuscript, or in the decision to publish the results.

\section{References}

1. Wang, J.; Song, Z.; Cheng, H.; Chen, L.; Deng, L.; Qi, Z. Multilevel screening of ionic liquid absorbents for simultaneous removal of $\mathrm{CO}_{2}$ and $\mathrm{H}_{2} \mathrm{~S}$ from natural gas. Sep. Purif. Technol. 2020, 248, 117053. [CrossRef]

2. Faramawy, S.; Zaki, T.; Sakr, A.-E. Natural gas origin, composition, and processing: A review. J. Nat. Gas Sci. Eng. 2016, 34, 34-54. [CrossRef]

3. Watanabe, S. Chemistry of $\mathrm{H}_{2} \mathrm{~S}$ over the surface of Common solid sorbents in industrial natural gas desulfurization. Catal. Today 2021, 371, 204-220. [CrossRef]

4. Zeng, Z.; Dlugogorski, B.Z.; Oluwoye, I.; Altarawneh, M. Combustion chemistry of COS and occurrence of intersystem cross-ing. Fuel 2021, 283, 119257. [CrossRef]

5. Alzueta, M.U.; Pernía, R.; Abián, M.; Millera, Á.; Bilbao, R. $\mathrm{CH}_{3} \mathrm{SH}$ conversion in a tubular flow reactor. Experiments and ki-netic modelling. Combust. Flame 2019, 203, 23-30. [CrossRef]

6. Kahyarian, A.; Nesic, S. H2S corrosion of mild steel: A quantitative analysis of the mechanism of the cathodic reaction. Electrochim. Acta 2019, 297, 676-684. [CrossRef]

7. Latosov, E.; Loorits, M.; Maaten, B.; Volkova, A.; Soosaar, S. Corrosive effects of $\mathrm{H}_{2} \mathrm{~S}$ and $\mathrm{NH}_{3}$ on natural gas piping systems manufactured of carbon steel. Energy Procedia 2017, 128, 316-323. [CrossRef]

8. Yi, H.; Tao, T.; Zhao, S.; Yu, Q.; Gao, F.; Zhou, Y.; Tang, X. Promoted adsorption of methyl mercaptan by $\gamma-\mathrm{Al}_{2} \mathrm{O}_{3}$ catalyst loaded with $\mathrm{Cu} / \mathrm{Mn}$. Environ. Technol. Innov. 2021, 21, 101349. [CrossRef]

9. Fu, Y.; Chen, J.; Zhang, H. Synthesis of $\mathrm{Fe}_{2} \mathrm{O}_{3}$ nanowires by oxidation of iron. Chem. Phys. Lett. 2001, 350, 491-494. [CrossRef]

10. Shi, C.; Chen, Y.; Liu, H.; Cui, G.; Ju, L.; Chen, L. Adsorption and gas-sensing characteristics of a stoichiometric $\alpha-\mathrm{Fe}_{2} \mathrm{O}_{3}(001)$ nano thin film for carbon dioxide and carbon monoxide with and without pre-adsorbed $\mathrm{O}_{2}$. RSC Adv. 2016, 6, 3514-3525. [CrossRef]

11. Saritas, S.; Kundakci, M.; Coban, O.; Tuzemen, S.; Yildirim, M. Ni:Fe $\mathrm{O}_{3}, \mathrm{Mg}: \mathrm{Fe}_{2} \mathrm{O}_{3}$ and $\mathrm{Fe}_{2} \mathrm{O}_{3}$ thin films gas sensor application. Phys. B Condens. Matter 2018, 541, 14-18. [CrossRef]

12. Hitam, C.; Jalil, A.; Izan, S.; Azami, M.; Hassim, M.; Chanlek, N. The unforeseen relationship of $\mathrm{Fe}_{2} \mathrm{O}_{3}$ and $\mathrm{ZnO}$ on fibrous silica KCC-1 catalyst for fabricated Z-scheme extractive-photooxidative desulphurization. Powder Technol. 2020, 375, 397-408. [CrossRef]

13. Song, Z.; Wang, B.; Yu, J.; Ma, C.; Zhou, C.; Chen, T.; Yan, Q.; Wang, K.; Sun, L. Density functional study on the heterogeneous oxidation of $\mathrm{NO}$ over $\alpha-\mathrm{Fe}_{2} \mathrm{O}_{3}$ catalyst by $\mathrm{H}_{2} \mathrm{O}_{2}$ : Effect of oxygen vacancy. Appl. Surf. Sci. 2017, 413, 292-301. [CrossRef]

14. Ling, L.; Song, J.; Zhao, S.; Zhang, R.; Wang, B. DFT study on the effects of defect and metal-doping on the decomposition of $\mathrm{H}_{2} \mathrm{~S}$ on the $\alpha-\mathrm{Fe}_{2} \mathrm{O}_{3}(0001)$ surface. RSC Adv. 2014, 4, 22411-22418. [CrossRef] 
15. Li, F.; Shi, C.; Wang, X.; Cui, G.; Wang, D.; Chen, L. The important role of oxygen defect for NO gas-sensing behavior of $\alpha$-Fe ${ }_{2} \mathrm{O}_{3}$ (001) surface: Predicted by density functional theory. Comput. Mater. Sci. 2018, 146, 1-8. [CrossRef]

16. Chen, C.; Zhao, C.; Zhou, X.; Chen, J.; Chen, L.; Li, F. DFT study on the interaction of $\mathrm{H}_{2} \mathrm{O}$ and $\mathrm{O}_{2}$ with $\alpha$-Fe $\mathrm{F}_{2} \mathrm{O}_{3}(001)$ surface. Vacuum 2021, 188, 110164. [CrossRef]

17. Hao, M.; Zeng, W.; Li, Y.Q. Adsorption mechanism of $\mathrm{H}_{2} \mathrm{~S}$ and $\mathrm{CH}_{3} \mathrm{SH}$ on $\mathrm{Fe}(110)$ surface: A density functional theory study. Physica E 2022, 135, 114938. [CrossRef]

18. Li, B.; Zhou, Q.; Peng, R.; Liao, Y.; Zeng, W. Adsorption of $\mathrm{SF}_{6}$ decomposition gases $\left(\mathrm{H}_{2} \mathrm{~S}, \mathrm{SO}_{2}, \mathrm{SOF}_{2}\right.$ and $\left.\mathrm{SO}_{2} \mathrm{~F}_{2}\right)$ on $\mathrm{Sc}-\mathrm{doped}$ $\mathrm{MoS}_{2}$ surface: A DFT study. Appl. Surf. Sci. 2021, 549, 149271. [CrossRef]

19. Shang, J.; Li, C.; Tang, X.; Du, A.; Liao, T.; Gu, Y.; Ma, Y.; Kou, L.; Chen, C. Multiferroic decorated $\mathrm{Fe}_{2} \mathrm{O}_{3}$ monolayer predicted from first principles. Nanoscale 2020, 12, 14847-14852. [CrossRef] [PubMed]

20. Ta, H.T.T.; Tieu, A.; Zhu, H.; Yu, H.; Tran, N.V. A First-Principles Study of Impurity-Enhanced Adhesion and Lubricity of Gra-phene on Iron Oxide Surface. J. Phys. Chem. C 2021, 125, 4310-4321. [CrossRef]

21. Clark, S.J.; Segall, M.D.; Pickard, C.J.; Hasnip, P.J.; Probert, M.I.J.; Refson, K.; Payne, M.C. First Principles Methods Using CASTEP. Z. Krist. Cryst. Mater. 2005, 220,567-570. [CrossRef]

22. Meunier, M. Introduction to materials studio. In EPJ Web of Conferences; EDP Sciences: Les Ulis, France, 2012; Volume 10, p. 04001.

23. Troullier, N.; Martins, J.L. Efficient pseudopotentials for plane-wave calculations. Phys. Rev. B 1991, 43, 1993. [CrossRef]

24. Ziesche, P.; Kurth, S.; Perdew, J.P. Density functionals from LDA to GGA. Comput. Mater. Sci. 1998, 11, 122-127. [CrossRef]

25. Perdew, J.P.; Burke, K.; Ernzerhof, M. Generalized Gradient Approximation Made Simple. Phys. Rev. Lett. 1996, 77, 3865, Erratum in 1997, 78, 1396. [CrossRef] [PubMed]

26. Head, J.D.; Zerner, M.C. A Broyden-Fletcher-Goldfarb—Shanno optimization procedure for molecular geometries. Chem. Phys. Lett. 1985, 122, 264-270. [CrossRef]

27. Froyen, S. Brillouin-zone integration by Fourier quadrature: Special points for superlattice and supercell calculations. Phys. Rev. B 1989, 39, 3168-3172. [CrossRef] [PubMed]

28. Rohrbach, A.; Hafner, J.; Kresse, G. Molecular adsorption on the surface of strongly correlated transition-metal oxides: A case study for $\mathrm{CO} / \mathrm{NiO}(100)$. Phys. Rev. B 2004, 69, 075413. [CrossRef]

29. Dudarev, S.L.; Botton, G.A.; Savrasov, S.Y.; Humphreys, C.J.; Sutton, A.P. Electron-energy-loss spectra and the structural stability of nickel oxide: An LSDA+U study. Phys. Rev. B 1998, 57, 1505-1509. [CrossRef]

30. Bandyopadhyay, A.; Velev, J.; Butler, W.; Sarker, S.K.; Bengone, O. Effect of electron correlations on the electronic and magnet-ic structure of Ti-doped $\alpha$-hematite. Phys. Rev. B 2004, 69, 174429. [CrossRef]

31. Sandratskii, L.M.; Uhl, M.; Kübler, J. Band theory for electronic and magnetic properties of. J. Phys. Condens. Matter 1996, 8 , 983-989. [CrossRef]

32. Wong, K.; Zeng, Q.H.; Yu, A.B. Electronic Structure of Metal (M = Au, Pt, Pd, or Ru) Bilayer Modified $\alpha$-Fe $\mathrm{F}_{2} \mathrm{O}_{3}(0001) \mathrm{Surfaces}_{\text {. J }}$. Phys. Chem. C 2011, 115, 4656-4663. [CrossRef]

33. Rohrbach, A.; Hafner, J.; Kresse, G. Ab initio study of the (0001) surfaces of hematite and chromia: Influence of strong electronic correlations. Phys. Rev. B 2004, 70, 125426. [CrossRef]

34. Glasscock, J.; Barnes, P.; Plumb, I.; Bendavid, A.; Martin, P. Structural, optical and electrical properties of undoped polycrystal-line hematite thin films produced using filtered arc deposition. Thin Solid Films 2008, 516, 1716-1724. [CrossRef]

35. Merchant, P.; Collins, R.; Kershaw, R.; Dwight, K.; Wold, A. The electrical, optical and photoconducting properties of $\mathrm{Fe}_{2-\mathrm{x}} \mathrm{Cr}_{\mathrm{x}} \mathrm{O}_{3}$ $(0 \leq \mathrm{x} \leq 0.47)$. J. Solid State Chem. 1979, 27, 307-315. [CrossRef]

36. Zhang, Y.; Zeng, W.; Li, Y. $\mathrm{NO}_{2}$ and $\mathrm{H}_{2}$ sensing properties for urchin-like hexagonal $\mathrm{WO}_{3}$ based on experimental and first-principle investigations. Ceram. Int. 2019, 45, 6043-6050. [CrossRef]

37. Zhang, Y.; Zeng, W.; Li, Y. Computational study of surface orientation effect of rutile $\mathrm{TiO}_{2}$ on $\mathrm{H}_{2} \mathrm{~S}$ and CO sensing mechanism. Appl. Surf. Sci. 2019, 495, 143619. [CrossRef]

38. Guerra, C.F.; Handgraaf, J.W.; Baerends, E.J.; Bickelhaupt, F.M. Voronoi deformation density (VDD) charges: Assessment of the Mulliken, Bader, Hirshfeld, Weinhold, and VDD methods for charge analysis. J. Comput. Chem. 2004, 25, 189-210. [CrossRef]

39. Finger, L.W.; Hazen, R.M. Crystal structure and isothermal compression of $\mathrm{Fe}_{2} \mathrm{O}_{3}, \mathrm{Cr}_{2} \mathrm{O}_{3}$, and $\mathrm{V}_{2} \mathrm{O}_{3}$ to 50 kbars. J. Appl. Phys. 1980, 51, 5362. [CrossRef]

40. Wang, X.-G.; Weiss, W.; Shaikhutdinov, S.K.; Ritter, M.; Petersen, M.; Wagner, F.; Schlögl, R.; Scheffler, M. The hematite $\left(\alpha-\mathrm{Fe}_{2} \mathrm{O}_{3}\right)$ (0001) surface: Evidence for domains of distinct chemistry. Phys. Rev. Lett. 1998, 81, 1038. [CrossRef]

41. Zhang, Y.; Liu, J. Density Functional Theory Study of Arsenic Adsorption on the $\mathrm{Fe}_{2} \mathrm{O}_{3}$ (001) Surface. Energy Fuels 2019, 33, 1414-1421. [CrossRef]

42. Alvarez-Ramırez, F.; Martınez-Magadán, J.; Gomes, J.; Illas, F. On the geometric structure of the (0001) hematite surface. Surf. Sci. 2004, 558, 4-14. [CrossRef]

43. Perepichka, D.F.; Bryce, M.R. Molecules with Exceptionally Small HOMO-LUMO Gaps. Angew. Chem. Int. Ed. 2005, 44, 5370-5373. [CrossRef] [PubMed]

44. Wang, Z.C.; Zeng, W.; Gu, L.; Saito, M.; Tsukimoto, S.; Ikuhara, Y. Atomic scale structure and electronic property of the LaA-1O $3 / \mathrm{TiO}_{2}$ interface. J. Appl. Phys. 2010, 108, 113701. [CrossRef] 